Original Research Article

\title{
A prospective pharmacovigilance study to evaluate adverse effect profile of first line anti-tubercular drugs in newly diagnosed sputum positive patients
}

\author{
Akhil Agrawal, Uma A. Bhosale*
}

Department of Pharmacology, SKNMC and GH, Narhe, Ambegaon, Pune, Maharashtra India

Received: 21 November 2017 Accepted: 28 December 2017

\section{*Correspondence to: Dr. Uma A. Bhosale, Email: umabhosale2000@ gmail.com}

Copyright: (C) the author(s), publisher and licensee Medip Academy. This is an openaccess article distributed under the terms of the Creative Commons Attribution NonCommercial License, which permits unrestricted noncommercial use, distribution, and reproduction in any medium, provided the original work is properly cited.

\begin{abstract}
Background: Tuberculosis (TB) continues to remain one of the most pressing health problems in India with highest TB burden country in the world. Antitubercular therapy (ATT) induced organ toxicities are potentially serious ADRs of first line ATT regimen. The underlying mechanism of ATT-induced ADRs especially hepatotoxicity and the factors predisposing to its incidence which is significantly high in Indians are not clearly understood. It's vital to emphasize on ATT induced ADRs as it has direct influence on therapeutic outcome; result in high dropout rate and potential to develop MDR/XDR cases. ADR monitoring help us to revise the treatment protocol thereby improve treatment adherence and therapeutic outcome. Objective of this study is therefore designed to explore and monitor ADRs of first line anti-TB drugs.
\end{abstract}

Methods: In this prospective observational study 60 TB patients (18-70 yrs) of either sex, newly sputum positive with normal parameters were included. Patients were followed up for six months aiming primarily to assess rate of ADRs and to identify preventable and potentially serious ADRs of anti-TB drugs. The ADRs of ATT on various organ systems (heart, kidney and liver), biochemical and haematological parameters were assessed and compared after 2 and 6 months; gender and age specific adverse events were also studied. Data obtained was analysed using student's t-test of OpenEpi statistical software.

Results: Study clearly revealed that ATT exhibit significant increase in toxicity markers viz. liver enzymes $(p<0.01)$, urea and creatinine $(p<0.01), \operatorname{ESR}(p<0.05)$ and PTINR $(\mathrm{p}<0.01)$, wherein decrease in $\mathrm{Hb} \%(\mathrm{p}<0.01)$ when compared to baseline.

Conclusions: ATT related ADRs is the major cause of dropouts and development of MDR/XDR cases. It's crucial to develop strategies to ameliorate ADRs both to improve the quality of patient care and to control TB safely. The data obtained from present study may be helpful in developing these effective strategies.

Keywords: ATT, CPK, DOTS, KFT, LFT

\section{INTRODUCTION}

TB is the most rampant communicable infectious disease on earth and remains out of control in many developing countries. It is the single most common cause of death in individuals aged 15-49 yrs. $^{1}$ TB remains a major health problem. In 2012, an estimated 8.6 million people developed $\mathrm{TB}$ and 1.3 million died from the disease (including HIV-positive). The number of TB deaths is unacceptably large given that most are preventable.
Significant mortality rate estimated in 2012 among women, as well as among children are really dreadful. It has reduced quality of life of patient which includes both social and economic factors. About 20 yrs ago, WHO declared TB as global public health emergency and thereafter major progress has been made. Globally, the TB mortality rate has fallen by $45 \%$ since 1990 and incidence rate has been falling in most parts of the world. ${ }^{2}$ Despite the positive therapeutic effects, studies have Shown that utilization of multidrug regimens can cause undesirable 
adverse drug reactions (ADRs) of varying degrees of severity, such as hepatotoxicity, gastrointestinal (GI) disorders, allergic reactions, arthralgia, neurological disorders, and so on. Studies suggest that more than $5 \%$ of the patients on anti-TB drugs develop ADRs. ${ }^{3}$

Earlier prospective studies conducted at Mumbai and Imphal (Manipur) have revealed ADR incidence of $14.56 \%$ and $69.01 \%$ respectively. ${ }^{1,3}$ Dermatological and gastrointestinal (GI) ADRs were among most common reported. ${ }^{1,3}$ Female ADRs predominance was noted over males in these studies. More or less similar results were obtained in studies carried out in Bangladesh and Korea, where ADR incidence was found to be $78.75 \%$ and $52.6 \%$ respectively. ${ }^{4,5}$ Whereas, predominant dermatological ADRs (42.95\% vs. $15.99 \%)$ were reported in Bangladesh while GI ADRs in Korea (19.3\% vs. $17.7 \%)^{4,5}$

Based on the results above, it is seen that different studies have different rate of incidence, the most common ADR and predominance in specific gender. Hence, this study intends to confirm and re-evaluate these results and to bring out some clarity in consequences. It also proposes to study the median time required for the ADR to appear after beginning of treatment and to assess the severity of each ADR based on various clinical and laboratory scales which is not included in previous studies.

\section{METHODS}

This prospective Pharmacovigilance study included 60 cases of newly sputum positive patients on first line antitubercular therapy with normal biochemical and haematological parameters at screening (sample size calculated by OpenEpi software with 95\% CI) which included both outpatients and inpatients. ${ }^{6}$

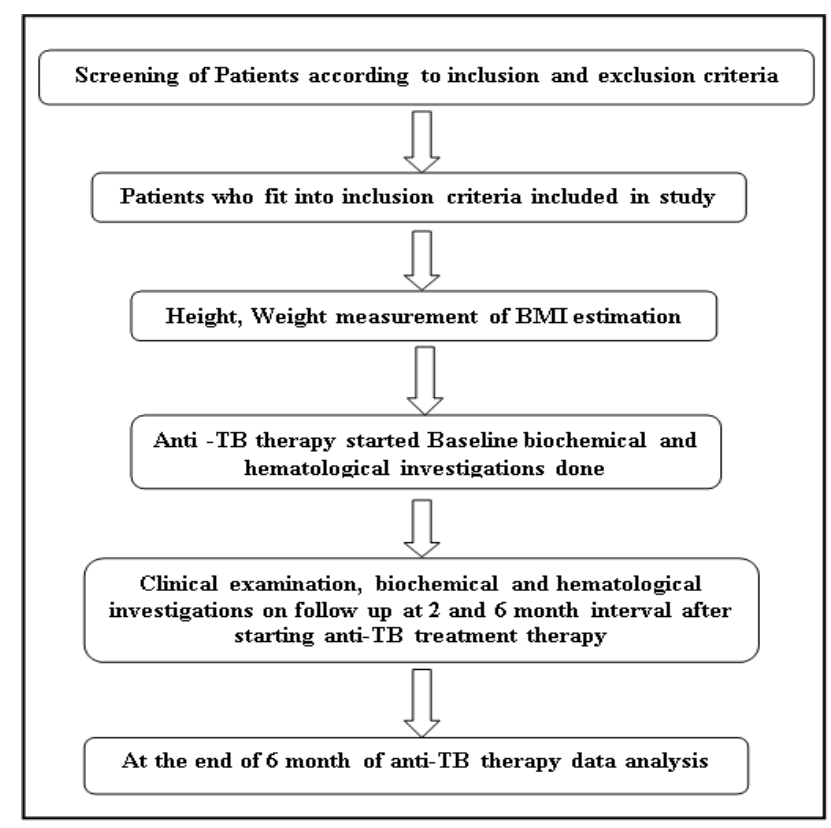

Figure 1: Study flow chart.
Patients of either sex with an age range between 18 and $70 y$ rs were included in the study.

While patients with chronic diseases like IHD, arthritis, cirrhosis, cancer etc. were excluded from study (Figure 1). Informed consent was taken from all patients after discussing purpose and benefits of the study. ADR severity and causality were assessed using Hartwig and Siegel Severity assessment scale and Narango Algorithm respectively. ${ }^{1}$ ADRs grading was done using various common toxicity criteria. ${ }^{7-11}$

\section{RESULTS}

This prospective, Pharmacovigilance study included 60 adult newly diagnosed sputum positive patients of either sex, who were on first line anti-TB therapy. Out of 60 enrolled patients 34 male, 31 between age group 21-40 yrs and 48 were non-smokers with mean BMI 21.83.

Table 1: Effects of first line anti-TB drugs on various biochemical parameters highlighting organ toxicities.

\begin{tabular}{|lcll|}
\hline Investigations & $\begin{array}{l}\text { Baseline } \\
(\text { Mean } \pm \text { SD) }\end{array}$ & $\begin{array}{l}\text { 2 Month } \\
(\text { Mean } \pm \text { SD })\end{array}$ & $\begin{array}{l}\text { 6 Month } \\
(\text { Mean } \pm \text { SD })\end{array}$ \\
\hline $\begin{array}{l}\text { Blood urea } \\
(\mathrm{mg} / \mathrm{dl})\end{array}$ & $16.76 \pm 4.24$ & $24.33 \pm 1.41^{* *}$ & $25.7 \pm 2.82^{* *}$ \\
\hline $\begin{array}{l}\text { Serum } \\
\text { Creatinine }\end{array}$ & $0.75 \pm 0.07$ & $0.91 \pm 0.28$ & $0.96 \pm 0.13^{* *}$ \\
\hline $\begin{array}{l}\text { Uric acid } \\
\text { (mg/dl) }\end{array}$ & $4.49 \pm 0.63$ & $5.04 \pm 0.70^{*}$ & $4.91 \pm 0.70^{*}$ \\
\hline $\begin{array}{l}\text { Total } \\
\text { bilirubin } \\
\text { (mg/dl) }\end{array}$ & $0.82 \pm 0.11$ & $0.85 \pm 0.11$ & $0.88 \pm 0.10^{*}$ \\
\hline $\begin{array}{l}\text { Direct } \\
\text { bilirubin } \\
\text { (mg/dl) }\end{array}$ & $0.13 \pm 0.04$ & $0.16 \pm 0.05^{*}$ & $0.19 \pm 0.05^{*}$ \\
\hline ALT(U/dl) & $38.2 \pm 4.94$ & $40.45 \pm 9.19$ & $41.66 \pm 12.02^{* * *}$ \\
\hline AST (U/dl) & $38.66 \pm 8.48$ & $41.05 \pm 6.36$ & $42.01 \pm 14.14^{* * *}$ \\
\hline $\begin{array}{l}\text { Alkaline } \\
\text { phosphatase }\end{array}$ & $62.3 \pm 7.07$ & $68.7 \pm 7.07$ & $67.4 \pm 42.42^{*}$ \\
\hline CPK & $51.16 \pm 15.3$ & $61.38 \pm 33.26$ & $61.18 \pm 19.15$ \\
\hline
\end{tabular}

$\mathrm{N}=60, \mathrm{P}<0.05$ is significant. $\mathrm{P}<0.05 * \mathrm{P}<(<0.01)^{* *}$ Statistical analysis was done based on values at 2 months and 6 months in comparison with baseline values using paired student $t$ test.

Table 2: Effects of first line anti-TB drugs on various haematological parameters.

\begin{tabular}{|llll|}
\hline Investigations & $\begin{array}{l}\text { Baseline } \\
(\text { Mean } \pm \text { SD })\end{array}$ & $\begin{array}{l}\text { 2 Month } \\
(\text { Mean } \pm \text { SD })\end{array}$ & $\begin{array}{l}\text { 6 Month } \\
(\text { Mean } \pm \text { SD })\end{array}$ \\
\hline $\mathrm{Hb}(\mathrm{gm} / \mathrm{dl})$ & $11.06 \pm 0.70$ & $9.95 \pm 0.70^{* *}$ & $9.56 \pm 1.41^{* *}$ \\
\hline $\begin{array}{l}\mathrm{TLC}(1000 \\
\left.\text { cell/mm } \mathrm{mm}^{3}\right)\end{array}$ & $6.2 \pm 0.70$ & $6.1 \pm 0.77$ & $5.9 \pm 1.06^{*}$ \\
\hline ESR & $14.6 \pm 4.94$ & $17.15 \pm 7.07^{*}$ & $17.58 \pm 2.12^{*}$ \\
\hline $\begin{array}{l}\text { Platelet count } \\
\text { (lakhs/mcl) }\end{array}$ & $2.87 \pm 0.4$ & $2.58 \pm 0.14^{*}$ & $2.33 \pm 0.54^{*}$ \\
\hline PTINR & $0.89 \pm 0.07$ & $0.93 \pm 0.04^{*}$ & $0.96 \pm 0.02^{* *}$ \\
\hline
\end{tabular}

$\mathrm{N}=60, \mathrm{P}<0.05$ is significant. $\mathrm{P}<0.05 * \mathrm{P}<(<0.01)^{* *}$ Statistical analysis was done based on values at 2 months and 6 months in comparison with baseline values using paired student $t$ test. 
Table 3: Systemic ADRs observed in study population.

\begin{tabular}{|llll|}
\hline Types of ADR & No. of patients & $\%$ & $\begin{array}{l}\text { Onset } \\
\text { (days) }\end{array}$ \\
\hline GIT & 31 & 52 & 15 \\
\hline Skin & 8 & 13 & 70 \\
\hline Hepatic & 3 & 5 & 120 \\
\hline Renal & 3 & 5 & 22 \\
\hline Joint pain & 2 & 3.3 & - \\
\hline Ototoxicity & 2 & 3.3 & 86 \\
\hline
\end{tabular}

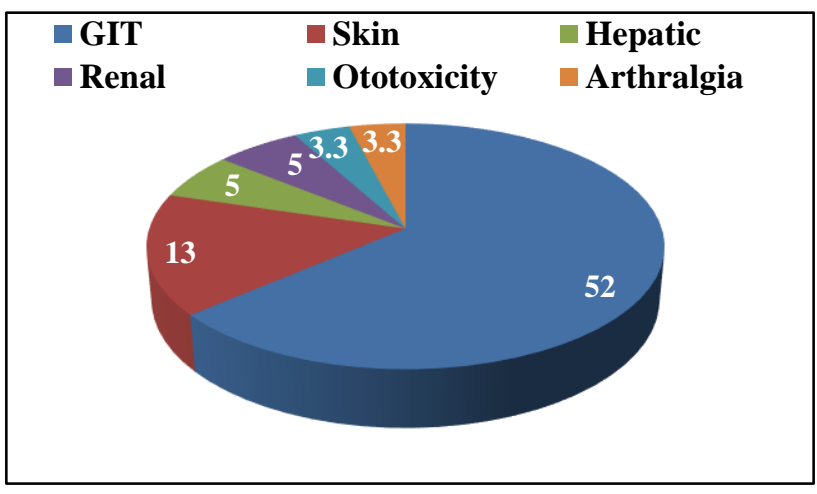

Figure 2: Systemic ADRs observed in study population.

Table 4: Frequency and severity of systemic ADRs.

\begin{tabular}{|c|c|c|c|}
\hline Frequency & $\begin{array}{l}\text { Baseline } \\
(\%)\end{array}$ & $\begin{array}{l}2 \text { months } \\
(\%)\end{array}$ & $\begin{array}{l}6 \text { months } \\
(\%)\end{array}$ \\
\hline \multicolumn{4}{|l|}{ GIT } \\
\hline Nausea & 50 & 36 & 28 \\
\hline Vomiting & 38 & 25 & 16 \\
\hline $\begin{array}{l}\text { Abdominal } \\
\text { distress }\end{array}$ & 32 & 23 & 10 \\
\hline \multicolumn{4}{|c|}{ Dermatology } \\
\hline Rash & 0 & 13.3 & 3.3 \\
\hline \multicolumn{4}{|c|}{ Hepatobiliary } \\
\hline Jaundice & - & 3.3 & 3.3 \\
\hline \multicolumn{4}{|l|}{ Ototoxicity } \\
\hline Tinnitus & - & 1.7 & 3.3 \\
\hline Vertigo & - & 1.7 & 3.3 \\
\hline \multicolumn{4}{|c|}{ Bone and joints } \\
\hline Arthralgia & - & 5 & 1.6 \\
\hline Severity & Mild (\%) & Moderate (\%) & Severe $(\%)$ \\
\hline \multicolumn{4}{|c|}{ the } \\
\hline Nausea & 93 & 7 & - \\
\hline Vomiting & 100 & - & - \\
\hline $\begin{array}{l}\text { Abdominal } \\
\text { distress }\end{array}$ & 91 & 9 & - \\
\hline \multicolumn{4}{|c|}{ Dermatology } \\
\hline Rash & 75 & 25 & 0 \\
\hline \multicolumn{4}{|c|}{ Hepatobiliary } \\
\hline Jaundice & 100 & - & - \\
\hline \multicolumn{4}{|l|}{ Ototoxicity } \\
\hline Tinnitus & 100 & - & - \\
\hline Vertigo & 100 & - & - \\
\hline \multicolumn{4}{|c|}{ Bone and joints } \\
\hline Arthralgia & 100 & - & - \\
\hline
\end{tabular}

Effects of first line anti-TB drugs on various biochemical parameters suggestive of organ toxicity and haematological parameters, at follow up and end of therapy are presented in tables 1 and 2 respectively. While details of systemic adverse effects of anti-TB drugs are presented (Table 3,4 and Figure 2).

Incidence of ADRs was found to be higher in elderly $(60 \%)$ male $(55 \%)$ and with history of smoking $(58 \%)$. Majority (81\%) ADRs were probable and of mild (83\%) category (Table 4).

\section{DISCUSSION}

Increasing incidence of ADRs leads to discontinuation of anti- TB treatment (ATT) and potential to develop MDR/XDR cases. The studies depicting ADR potential and its influence on patient compliance and therapeutic outcome in Indian setup are lacking. It is very essential to identify these ADRs at the earliest, treat them and reduce morbidity and mortality associated with them thereby improve compliance. Present prospective observational study therefore was intended to analyse the clinical findings, haematological and biochemical parameters of adverse drug effects of anti-TB drugs in patients under DOTS therapy during intensive phase of treatment. A total of 60 newly diagnosed tuberculosis patients who were given DOTS therapy were enrolled for the study. Out of 60 patients, 32 developed adverse drug reactions (53\%) this incidence was found to be negligible in studies conducted in Malaysia and Canada however comparable with the studies conducted in India. ${ }^{4,5,12,13}$ The reason behind high incidence rate in India need to be critically evaluated as it has direct impact on the therapeutic outcome.

In present study anti-TB drugs were found to cause organ toxicity over period of 6 months therapy, which become evident from significant increase in blood urea $(p<0.01)$, AST $(\mathrm{p}<0.01)$. Though serum creatinine, uric acid, ALT, alkaline phosphatase and bilirubin levels were significantly increased compared to baseline they were found to be within normal limits. Similar such results were reported by few earlier researchers (Table 1). ${ }^{14,17}$

In the present study, the haematological factors were significantly affected. Amongst the haematological parameters $\mathrm{Hb} \%$ was reduced significantly $(\mathrm{p}<0.01)$, other parameters such as ESR, TLC, Platelet count and PTINR though affected significantly but they were within normal limits. Anti-TB drugs are known to cause anemia and same was revealed in this study (Table 2 ). ${ }^{18}$

The incidence of organ systems most affected by ADRs were the gastrointestinal tract [GIT] $(52 \%)$ followed by skin $(13 \%)$, hepatobiliary system $(5 \%)$, ototoxicity $(3.3 \%)$ and renal system (5\%), Joint pain (3.3\%) respectively. Hepatic and ototoxic adverse observed late while GIT and renal adverse among the early onset adverse (Table 3, Figure 2). 
Causality evaluation of all ADRs revealed majority (90\%) in probable category while only $(10 \%)$ in possible category. Frequency of ADRs was significantly higher in females $(55 \%)$ than males $(45 \%)$. Females were significantly more predisposed to development of ADRs. This phenomenon is attributed to the alteration of drug responses mainly due to their lower body weight compared to the males. ${ }^{19}$ Several studies conducted in India had similar results. As per studies conducted in North India, Mumbai and Manipur females were predominantly associated with ADRs., ${ }^{3,20,21}$ The present study reestablishes the finding from previous literature. Based on Hartwig and Siegel severity scale, all ADRs were mild in severity except (10\% of GIT) ADRs which were moderate but there were no severe reactions.

In the present study, the frequency of ADRs in older age group ( $>40$ years) was significantly higher as compared to younger age group ( $<40$ years). In a study conducted in Iran, a positive correlation was found between higher age group and ADR frequency but no such finding was given by studies conducted in Malaysia and Canada. ${ }^{4,22}$ In studies conducted in India, a study in Mumbai showed significant association between higher age group and ADR frequency while studies in Manipur and north India showed no such association. ${ }^{4,13,21}$ Age-related changes in drug disposition and pharmacodynamic responses is the reason behind variable clinical implications and ADRs. ${ }^{23}$ In the present study, the frequency of ADRs was significantly higher in patients with smoking habit. The reasons are unknown but previous literature has pointed towards the role of smoking in inducing hepatic enzymes.

\section{CONCLUSION}

This study showed that about $53 \%$ of TB patients who received DOTS therapy developed one or more ADR's. These side-effects may steer the patient to make a judgment for stopping the medications and finally the occurrence of drug resistance and an amplified healthcare cost. It highlighted the importance of developing strategies to ameliorate ADRs both to improve the quality of patient care and to control TB safely. Pharmacovigilance activities should be promoted not only for medical professionals but also for patients. These strategies may improve the patient adherence to treatment and therapeutic outcome.

Funding: No funding sources

Conflict of interest: None declared

Ethical approval: The study was approved by the Institutional Ethics Committee (Ethics/App/2014/278).

\section{REFERENCES}

1. Srinivasan R, Ramya G. Adverse Drug ReactionCausality Assessment. Int J Res Pharm Chem. 2011;1(3):606-12.

2. Merriam SB, Tisdell EJ. Qualitative Research: A Guide to Design and Implementation. John Wiley \& Sons, $4^{\text {th }}$ Edition; 24-Aug 2015.
3. Patel K, Kedia M, Bajpai D, Mehta S, Kshirsagar N, Gogtay N. Evaluation of the prevalence and economic burden of adverse drug reactions presenting to the medical emergency department of a tertiary referral centre: a prospective study. BMC Clin Pharmacol. 2007;7(1):8.

4. Sinha K. Adverse drug reactions in tuberculosis patients due to directly observed treatment strategy therapy: Experience at an outpatient clinic of a teaching hospital in the city of Imphal, Manipur, India. 2013;1(2):12-5.

5. Kuchekar AB, Pujari RR, Kuchekar SB, Dhole SN. Psoriasis: A comprehensive review. Int J Pharm Life Sci. 2011;2(6):857-77.

6. Dean AG, Sullivan KM, Soe MM. Open Epi. Open Source Epidemiologic Statistics for Public Health. Version 2.3.1. 2013.

7. Balaji A, Rashmi K, Devinder MT. Scoring systems in acne vulgaris. Indian J Dermatol Venereol Leprol. 2009 May;75(3):323.

8. Marrow BB. Common Toxicity Criteria (CTC) Allergy/Immunology Auditory /Hearing. 1999;1998:1-35.

9. Noonan KA. the Impact of Chemotherapy-Induced Nausea and Vomiting. 2005;3(1):16-21.

10. McCombe A, Baguley D, Coles R, McKenna L, McKinney C, Windle-Taylor P. Guidelines for the grading of tinnitus severity: The results of a working group commissioned by the British Association of Otolaryngologists, Head and Neck Surgeons, 1999. Clin Otolaryngol Allied Sci. 2001;26(5):388-93.

11. National Institute of Cancer. Common Terminology Criteria for Adverse Events. 2010;2009:0-71.

12. Yee D, Valiquette C, Pelletier M, Parisien I, Rocher I, Menzies D. Incidence of Serious Side Effects from First-Line Antituberculosis Drugs among Patients Treated for Active Tuberculosis. Am J Respir Crit Care Med. 2003;167(11):1472-7.

13. Hassan MK, A ASP, Nagar G, Chas P, Bokaro D, City $\mathrm{S}$, et al. Incidence of Adverse Drug Reaction Among the Tuberculosis Patients Treated Under Directly Observed Treatment Short course (DOTS) Regimen in North India. 2016;598-600.

14. Farazi A, Sofian M, Jabbariasl M, Keshavarz S. Adverse reactions to antituberculosis drugs in Iranian tuberculosis patients. Tuberculosis research and treatment. 2014 Nov 24;2014.

15. Gholami K, Kamali E, Mi SH. Evaluation of antituberculosis induced adverse reactions in hospitalized patients. Pharm Pract. 2006;4(3):134-8.

16. Xiang Y, Ma L, Wu W, Liu W, Li Y, Zhu X, et al. The incidence of liver injury in uyghur patients treated for TB in Xinjiang Uyghur Autonomous Region, China, and its association with hepatic enzyme polymorphisms NAT2, CYP2E1, GSTM1 and GSTT1. PLoS One. 2014;9(1):1-8.

17. Abera W, Cheneke W, Abebe G. Incidence of antituberculosis-drug-induced hepatotoxicity and associated risk factors among tuberculosis patients in 
Dawro Zone, South Ethiopia: A cohort study. Int J Mycobacteriol. 2016;5(1):14-20.

18. Oliva VM, Cezário GAG, Cocato R. Pulmonary tuberculosis: hematology, serum biochemistry and the relation with the disease duration. J Venom Anim Toxins incl Trop Dis. 2008;14(1):71-81.

19. WW Y, CC L. Antituberculosis drugs and hepatotoxicity Deep Dyve. Respirology. 2006;11(6):699-707.

20. Sonika U, Kar P. Antituberculous drug-induced liver injury: current perspective. Trop Gastroenterol. 2011;32(3):167-74.

21. Patidar D, Rajput MS, Nirmal NP, Savitri W. Implementation and evaluation of adverse drug reaction monitoring system in a tertiary care teaching hospital in Mumbai, India. Interdiscip Toxicol. 2013;6(1):41-6.

22. Shu CC, Lee CH, Lee MC, Wang JY, Yu CJ, Lee LN. Hepatotoxicity due to first-line anti-tuberculosis drugs: A five-year experience in a Taiwan medical centre. Int J Tuberc Lung Dis. 2013;17(7):934-9.

23. Berlinger $\mathrm{WG}$, Spector R. Adverse drug reactions in the elderly. Geriatrics. 1984;39(2):45-6,50-2,57-8.

Cite this article as: Agrawal A, Bhosale UA. A prospective pharmacovigilance study to evaluate adverse effect profile of first line anti-tubercular drugs in newly diagnosed sputum positive patients. Int J Basic Clin Pharmacol 2018;7:283-7. 